the characteristics of his forerunner long before he would himself acknowledge it.

None of the means that are ordinarily resorted to can suppress this sneeze; it simply means to announce that "Barkis is willin'," or would like to be, at least, that such an idea exists in the brain of its victim whether or not it can be properly and effectually reflected.

In all of the cases without an exception it would appear that the effect on the sneezing area has come and gone before the mental reflex stimulus has had time to reach its usual result of erectile perfection. A sneeze is one of the most typical examples of a nerve reflex and while the neurologist can only construct a beautiful theory to explain its incentive and conductive factors, pathologists agree that the final result is brought about by the swelling of the erectile tissue covering the turbinal bones. The histologic similarity between the turbinal tissues and the corpora cavernosa is quite sufficient to cause no sense of wonder or surprise when a mental impression that excites one should also excite the other even within pathologic bounds, although we are accustomed to regard the one as an entirely physiologic function and the other as distinctly pathologic.

The instances just cited prove, however, that it is only the turbinal tissue that possesses the dual capacity of responding to either a physiologic or a pathologic stimulus, also that its response to a mental stimulus always precedes the more important effect below and is lost before the distention of the corpora cavernosa is complete. It may be answered that a priapism is a pathologic condition and yet its beginning is physiologic.

Is it not fortunate too, that every time we get our feet wet the reflex result on this lower and larger erectile area is not the same that is so often produced on the turbinal tissue by an over stimulus from an external source?

It has not been my intention to treat this subject lightly. It is too closely allied to one that men generally, I believe, do not disregard, "with but a single thought." But seriously, I do think the paper could be more appropriately read before a section on neurology, unless we can claim that rhinologists can be neurologists too, at least in some particular directions when they choose.

I would be glad to receive a short history from any one of any case apropos to this subject of reflexes, and will promise to give due credit to the writer in a future, and I hope more comprehensive paper.

P. S.-During the short interval since $I$ read this paper I have been much gratified by receiving a number of letters from those who have seen its first epitomized report; many of these letters contain promises of short reports to me of cases either bearing directly on, or closely related to, the subject of erectile tissue reflexes. This subject is an evolution (so far as it has evolved) of the last six or eight years, and is not one of my choosing. Yet I confess a desire now to evolve it still further, if I can obtain sufficient data.

\section{A METHOD OF PRESERVING UNBOUND LITERATURE WITH SUGGESTIONS REGARDING A SYSTEM OF CLASSIFICATION.}

BY D. H. GaLloway, Ph.G., M.D. CHICAGO, ILL.

Probably the majority of physicians regard the unbound literature in their libraries as an unmitigated nuisance. They may see much of interest in this literature when received but the liklihood of being able to find it again when wanted is so remote that it is generally consigned to the waste basket. Any plan which will rescue this material from the waste basket and make it useful ought to be received favorably by every one who has realized how difficult the subject is. The problem of preserving unbound literature, so that it is available for convenient reference, is so difficult of solution that few attempt it and those few usually get swamped before the amount of material becomes very great.

A system to be valuable, must conform to the following requirements:

1. The scheme must be so simple that it can easily be carried in the mind and it must require the minimum of labor to establish and to keep it up.

2. Each article or subject must be accessible without delay or inconvenience and without handling or interfering with any other material which is not wanted.

3. The different articles on any subject must come together so that everything on that subject can be obtained as easily as any portion of it.

4. It must be capable of unlimited expansion so that all new material falls naturally in place beside that already in hand on the same subject and so that new subjects may be introduced without interfering with the previous arrangements.

5 . The arrangement must be compact; so that the library occupies no unused space. A hundred titles should occupy no more room when they constitute the entire library than they do when included in a library of 10,000 titles.

6. Every article or pamphlet should be a unit and capable of separate classification and of being moved independently of all others. The only exception to this being pamphlets or articles having exactly the same title.

Since the material is so easily damaged or destroyed everything in this library should be protected from injury and even wear, when not in actual use.

I have a system in use in my own library which, while not altogether unique, is entirely original with me. It conforms to all the requirements outlined above and as I know there are many who have felt the need of such a system, I have thought it worth while to publish mine. This system is applicable to any kind of literature and I carry it into all the realms of science included in my library. Unbound pam phlets of all kind are put into large envelopes and each envelope is treated as if it were a book. These envelopes may be sandwiched in with other books on the library shelves or they may be assigned to a section by themselves. I prefer the latter, thus drawing a sharp line between the bound and the unbound library. With this short statement of what I have done in my own library, I will go in to the details of my work so that others wishing to do likewise may be saved the great amount of experimental work which I went through before the difficulties were overcome and the system made satisfactory. After many changes and much experimenting, I have selected an envelope $6 \frac{1}{2}$ inches wide by $9 \frac{1}{2}$ inches long, open on the side and made of manilla paper. The paper should be heavy enough to handle easily and should be tough, so that it will not tear readily; it should be as light as possible, consistent with these two requirements. I have been unable to buy, in the market, 
envelopes that were entirely satisfactory, and recently had a lot made for me at an expense of $\$ 3.75$ per thousand, but when delivered, these envelopes were so irregular in size as to be unsatisfactory. In this great city of manufactures I feel sure that there is some one who can make them and make them right and I intend to keep looking until I find that person or firm.

The envelopes should have a flap, but be ungummed. I have bought and used gummed envelopes but after some experience with the flaps sticking in hot and damp weather, I took the trouble to wash the mucilage of the rest until I was able to get an envelope ungummed. Ready made envelopes are always gummed.

Now for the preparation of the material which is to go in the envelopes. The ideal form in which to have the literature for this method of classification is the "reprints" of articles which are obtained and distributed by many persons who write for medical journals. While these vary greatly in their value as contributions to medical knowledge and still more in their value to any particular individual, I carefully preserve every one which is sent to me. I also do another thing which is unusual and that is, acknowledge the receipt of them.

As a rule journals pay nothing for contributions from medical men, some give a few hundred reprints in lieu of other compensation and this would seem the least return any of them could make to the author. Since these reprints go only to the profession there can surely be no valid objection, from an ethical standpoint, to their distribution; for my part I would like to have in this form every article which interests me. Since however, not all articles of value are available in this form some other way must be devised for obtaining them. Of course a complete file of all the journals sub. scribed for, if bound and accompanied by a card index which has been very carefully made and conscientiously kept written up to date, will render available all that they contain. I prefer however the method I employ, which has many advantages and some disadvantages. The advantages will be obvious, the disadvantages I will point out as I proceed. When a journal comes in, I look through it reading all the articles that interest me and then put a check mark on it indicating that it has been read. When I have a little time to spare I take these up one at a time, take out the binding wires, and throw away the advertise. ments. Then selecting the first article which I wish to preserve. I tear out the leaves containing it and fasten them together at the back with two scraps of gummed label cut for the purpose, and used like a hinge, or instead of the label, small pieces of isinglass plaster. This keeps the leaves together and the articles may be piled up and handled without disturbing the order of the pages or losing any of the leaves. In this way all the original articles are disposed of.

There is one difficulty with the plan which immediately presents itself; one article will end and another begin on the same leaf. Usually one will not be wanted or the least desirable one will be sacrificed. If one of the articles begins a few lines from the bottom of the leaf, or the other ends a few lines from the top of the same leaf, I copy these few lines on the typewriter and thus save both. Or if there is too much to make that practicable and both are of value to me, I make a reference on the bottom of the page stating where the remainder of the article can be found.
This can not be done often, or much of the value of the system will be lost. If a large number of doctors should adopt this scheme there are some improvements in the journals which publishers might be prevailed upon to make which would obviate this objection. Paper is very cheap and postage is almost nothing, still I do not suppose they could be persuaded to leave a part of a leaf blank where one article ended and begin the next one on another leaf. There are some publishers who do this now, particularly in reports of scientific societies. There are in every journal a large number of small items which are of transient interest and they might be used to fill up the waste space; such an arrangement would improve the make-up of the journal. But until publishers are convinced that a large number of their subscribers desire such a change, we will probably be obliged to make the best of things as they are.

On every article, I write the name and date of the journal from which it was taken; this of course is unnecessary where that information is printed at the top of the page, as it is in some journals, and ought to be in all. The articles of a journal may thus be prepared for classification in less time than I have taken to write the description of it. If the journal is magazine size, the pages will be the proper size to go into the envelopes; some may need a little trimming. For this purpose $I$ have a board a foot wide and two or three feet long, a shoe knife with a shoemaker's sandstone on which to sharpen it and a straight edge of wood. The latter may be a thin strip of hard-wood flooring about two feet long. I lay the leaves on the board and trim to the size of a card-board pattern $6 \frac{1}{4}$ inches wide and $y \frac{1}{4}$ inches long, using the straight edge as a guide for the knife. Leaves from the double column journals of a larger size like the Journal of the American Medical Association must be folded once.

There are many small items in the back part of all journals which are worth preserving; such as I want are cut out and classified in the same manner; these may be pasted on pieces of manilla paper and the paper folded the proper size to go in the envelopes, under the appropriate subject. Many will object to "destroying" their journals, and where complete files are kept, bound and indexed on cards, it may not be desirable to do so. This scheme is intended to supplement the ordinary library, not to displace it. There are many articles in the literary and scientific magazines which I wish to preserve and by doing it in this manner I have them all where I can lay my fingers on any of them at a moment's notice, and with bulk and weight reduced to a minimum. The pamphlets, articles and clippings being cut, folded or pasted on paper the right size, must be classified before they are ready to go into the envelopes. The decimal classification originated by Mr. Melville Dewey and published by the Library Bureau of Boston, is at once the simplest and most comprehensive system with which $I$ am acquainted. This book costs $\$ 5$, and it is almost a necessity in any library. By this method all knowledge is divided into ten classes as follows: 0. General Works. 1. Philosophy. 2. Religion. 3. Sociology. 4. Philology. 5. Natural Science. 6. Useful Arts. 7. Fine Arts. 8. Literature. 9. History. Each class is separated into ten divisions, each division into ten sections, and each section into ten subsections and so on, each subject being divided into ten to any limit desired. After the first three 
figures the number is a decimal fraction. Medicine is classed with the useful arts, 600 , and occupies the numbers 610 to 620 , divided as shown in the following table.

610. Medicine. 611. Anatomy. 612. Physiology. 613. Personal Hygiene. 614. Public Health. 615. Materia Medica. Therapeutics. 616. Disease. Pathology. Treatment. 617. Surgery. Dentistry. 618. Gynecology. Obstetrics. 619. Comparative Medicine. Veterinary.

In classifying, one can see at a glance into which division an article goes, and with a lead pencil put on the appropriate number. All articles on medicine in general and not treating of any one division more than another are marked 610. In beginning such a classification with a large number of titles to work on, it is better to go through the whole lot, putting on the numbers thus far. Then sort them into ten piles, numbering from 0 to 9 according to the last figure. Tie up and put away all but one lot, take this lot, say Anatomy, 611, and go through it as before, this time putting a decimal point after the number already there and add a decimal number in the following manner:

611.1. Circulatory System.

611.2. Respiratory System.

611.3. Digestive System.

611.4. Glandular and Lymphatic System.

611.5. Ge Gito-urinary System.

611.7. Motor and Integumentary System.

611.8. Nervous System. Sensory Apparatus.

611.9. Regional Anatomy.

Now separate this lot according to the last figure, wrap up and label all but one of the divisions (this is to prevent mixing when the work is to be done at odd moments) and classify this division still further. Each paper of this lot now has the number, say, 611.8 and is further classified as follows:

611.8. (Anatomy of the Nervous System. Sensory Apparatus).

611.81. Brain and Meninges.

611.82. Spinal Cord and its Meninges.

611.83. Nerves.

611.84. Sight.

611.85. Hearing.

611.86. Smell.

611.87. Taste.

611.88. Touch.

611.89. Ganglia,

Many subjects, even in a private library, will require a third decimal and in some cases even a fourth. The classification can be continued in this manner to any degree of fineness which individual taste may suggest but it is not advisable usually to go beyond three decimal places.

When no further classification is necessary or desirable, the papers are ready to be put in the envelopes. Now separate the lot as before into smaller lots to correspond with the last figure of the number, put all the papers having the same number into the one envelope and put that number on the outside of the envelope in the upper left hand corner. If there are too many papers to go in one envelope use as many envelopes as may be necessary. It is not necessary to put more than the number on the envelope, but if desired the names of the authors of the various articles it contains may be written on the outside. I lay the envelope on the desk before me, back up, with little danger of its being abandon
the open flap toward me, write the number in the found a pleasure rather than a task. upper left hand corner, put in the material and tuck in the flap. The envelopes are then arranged on edge on the shelves in the book case, flap down and number to the right and in strict numerical order, the short way of the envelope vertical. All book cases are ten inches or more in depth and this allows the shelves to be placed seven or eight inches apart and the case will hold many more envelopes than it would if they stood on end. In arranging the envelopes on the shelves it is convenient to have some contrivance to prevent them from falling down. For this purpose I got a tinner to cut for me some pieces of galvanized iron ten inches long and three or four inches wide, and bend them in the middle to a right angle. One of these on a shelf with the end shoved under the envelopes will prevent their falling down until the shelf is full. An index is made of strips of card board an inch wide and an inch longer than the envelopes, shoved in between them and the appropriate number written on the projecting end; but few of these are necessary. The cataloguer meets with a number of difficulties which ought to be corrected. In the publication of articles which have been read before a society and discussed by the society, the paper and discussion appear in separate places; it would be better if the discussion should immediately follow the paper in the journal.

The authors' post-office address should be appended to the article. "Dr. Smith, N. Y.," is not enough. Authors should be careful to select such titles for their papers as will give some idea of their contents; one does not wish to read an article in order to find out the subject. It is difficult to index a paper with such titles as "Study of a few Suggestive Cases," "An Interesting Case," "A Surgical Fad."

All discoveries and improvements in medicine and surgery are first announced in the periodicals. Textbooks are scarcely out of the press before they are "back numbers." Details of original investigations seldom appear anywhere but in the medical journals, and if a doctor would keep abreast of the profession he must read them and not books alone; the one who depends on books will always be several years behind.

The capacity of the average brain for detailed information is soon reached, while the extent of the knowledge a professional man needs to use at one time or another is almost limitless. Since at best no man can have at command in his brain all the knowledge he must use, the best education is the one which enables him to find any available information when he has use for it. Any one who makes a lumber gallery of his mind, trying to crowd into it everything he can pick up, will soon find that his brain is not the workshop it ought to be.

Comparatively few men know the capabilities of their own libraries, and fewer still have any idea how to avail themselves of the vast storehouses of knowledge placed at their disposal in the great libraries of the country. The man who will classify and index his own library will find that he has introduced into the workshop of his mind an instrument of great power, for that itself is an education. If he will preserve in some such manner as I have outlined, the unbound literature which comes to him for almost nothing, his library will be doubled and his ability to profit by its contents will be more than doubled. The fascination of the work is so great that when well begun there is little danger of its being abandoned, for it will be ench 
For iwelve years I have used the envelope system for preserving scraps of information on all sorts of subjects, particularly personal ones. A drawer in my desk is divided into four compartments and in these, standing on end, are more than a thousand envelopes

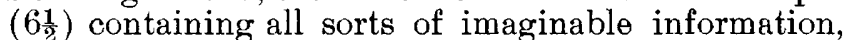
from teachers' certificates and college tickets to duplicates of ballots voted at various elections and clippings from newspapers and scientific periodicals. After filling some half-dozen scrap books, I found the material so inaccessible as to be next to useless. The envelope system is better than an index rerum for all things that will go into envelopes, for when the reference is found the material itself is at hand. I have kept a diary for over twenty-one years, and there is an entry for each and every day during that time. This record is a log-book rather than a diary, as that term is generally understood. In another book $I$ have an accurate account of all earnings and expenses since I have earned and spent money; I have the name of every person who has paid me money since I began earning money. In one place I have listed all the trips I have made on the railroads during my whole life, with the distance in each case and the total number of miles. In one place the names of all my patients and the names of those to whom I have administered anesthetics.

With lifelong habits of keeping accurate accounts and much experience in all sorts of methods for making available information regarding persons and things, $\mathbf{I}$ have come to the conclusion that the envelope system is the most nearly perfect that has yet been devised.

200 Oakwood Boulevard.

\section{SURGERY ONE HUNDRED YEARS AGO.} AN HISTORICAL STUDY

BY DR. GEORGE FISCHER.

DEDICATED TO THE GERMAN SURGICAL ASSOCIATION.

TRANSLATED FOR THE JOURNAL OF THE AMERICAN MEDICAL AGBOCIATION BY CARL H. VON KLEIN, A.M., M.D.

CHAPTER IV.- - NOTICE ON HOSPITALS.

(Continued from page 738.)

In respect to the number of patients the Hotel Dieu in Paris stood first, the General Hospital in Vienna second. The mortality was also greatest in the first mentioned hospital, so that, with the Berlin Charité, which held the second place; it had the reputation of a den of murder. One-third of all the mortality in Paris was in the hospitals, and one out of five patients in the Hôtel Dieu died. Trephining was no longer done there, for in forty years among a large number of operations, not one case had been successful. Tissot believed that without doubt fewer sick would die if they were allowed to lie under the blue sky and given only fresh water, since the hospital air alone could make every slight wound fatal. The mortality in the Vienna hospital was lower, as it was seldom more than half full. (Of the 30,764 patients received there in three years 24,900 were cared tor without charge.) The best hospitals were the English, particularly those in Edinburgh and Manchester, because of their isolated situation and well ventilated buildings. The mortality there amounted to only 4 per cent. Of the surgical patients, concerning whom statistics are unfortunately very meager, in the Charité in Berlin, between 10 and 15 per cent. died. The following figures show the extraordinarily small number of operations. In the year 1801, in the Berlin
Charité, among 523 surgical patients there were 30 operations, and two years later among 793, only 23 operations. The facts were similar in Friedrich's Hospital in Copenhagen, where in the year 1783 of 593 surgical patients 34 were operated upon, and two years later of 639 only 30 were operated upon. Among the 34 operations the majority were trephining, 8 , a fact very characteristic of that time. An overwhelm. ingly larger part of the hospitals of the last century were thoroughly bad. Built in unhealthful places, most of them had only small, low rooms, in which the patients, usually medical and surgical cases together, were as if buried. Dirt and stench abounded. The French especially lacked a sense of cleanliness, quite aside from their revolting custom of putting several patients in one bed. This custom was at that time so general that it is always especially mentioned in the descriptions of hospitals if each patient had his own bed. This nation has not to this day been able to free itself from the expensive and at the same time injurious custom of providing beds with curtains. As the directorships were often given by preferment, and to people without merit, who drew their money but left their business to inefficient assistants, abuses not only crowded into all departments, but science was quite extinguished. The cure of most diseases was very difficult, the simplest of them often assumed a malignant character. This was largely due to the neglect of the closets, sewers and ventilation. When one considers that even today a project is urged to alter our hospitals so as to admit fresh, pure air, that the question of ventilation is still everywhere felt to be one of the most important, one might suppose that our forefathers knew nothing of these things. However, this is not true. Even then they recognized in the infected air a source of great mortality, as well as the increasing danger in narrow rooms and the crowding of patients, but the majority of the physicians did little or nothing toward putting these ideas into practice.

One of the first to appreciate the value of ventilation and throw doors and windows wide open to admit fresh air, was the English military surgeon J. Pringle. His plans of improvement were originally made for field hospitals. Suffice it to say that his principle was as follows: We may lay it down as a rule that the more fresh air we let into hospitals, the less danger there is of breeding this distemper (hospital fever). The more fresh air, the less danger! He put so few patients in each room that one who did not understand the matter would think there was room for two or three times the number. A part of the boards were taken out of the floors in the field hospitals, and the garrets opened on to the roof. He knew in how incredibly short a time the air in narrow rooms was defiled, but recognized too the difficulty of remedying the evil when neither nurses nor patients could be convinced of the necessity of opening doors and windows. Those rooms were always the most healthful where the air entered through broken windows and other holes in the wall. (Written in the year 1752!) Pringle's contemporary, Stephen Hales, celebrated for his penetrating and accurate experimental researches, invented a ventilator in the form of a great mechanical bellows, in order to improve the air in prisons and ships. Pringle recommended this for the hospitals, and in winter fires in the fireplaces, which acted as ventilators. Only in cases where facilities for ventilation were lacking, would he purify the air with 